THE DOMINION OF CANADA'S 72-IN. TELESCOPE.

A LTHOUGH the reflecting telescope of the A Dominion Astrophysical Observatory, Victoria, B.C., is exceeded in size by the roo-in. Mt. Wilson reflector, now nearly completed, it has had the distinction of being for some months the largest in operation in the world. The Government of Canada is to be congratulated on carrying through to completion during the war this great undertaking,

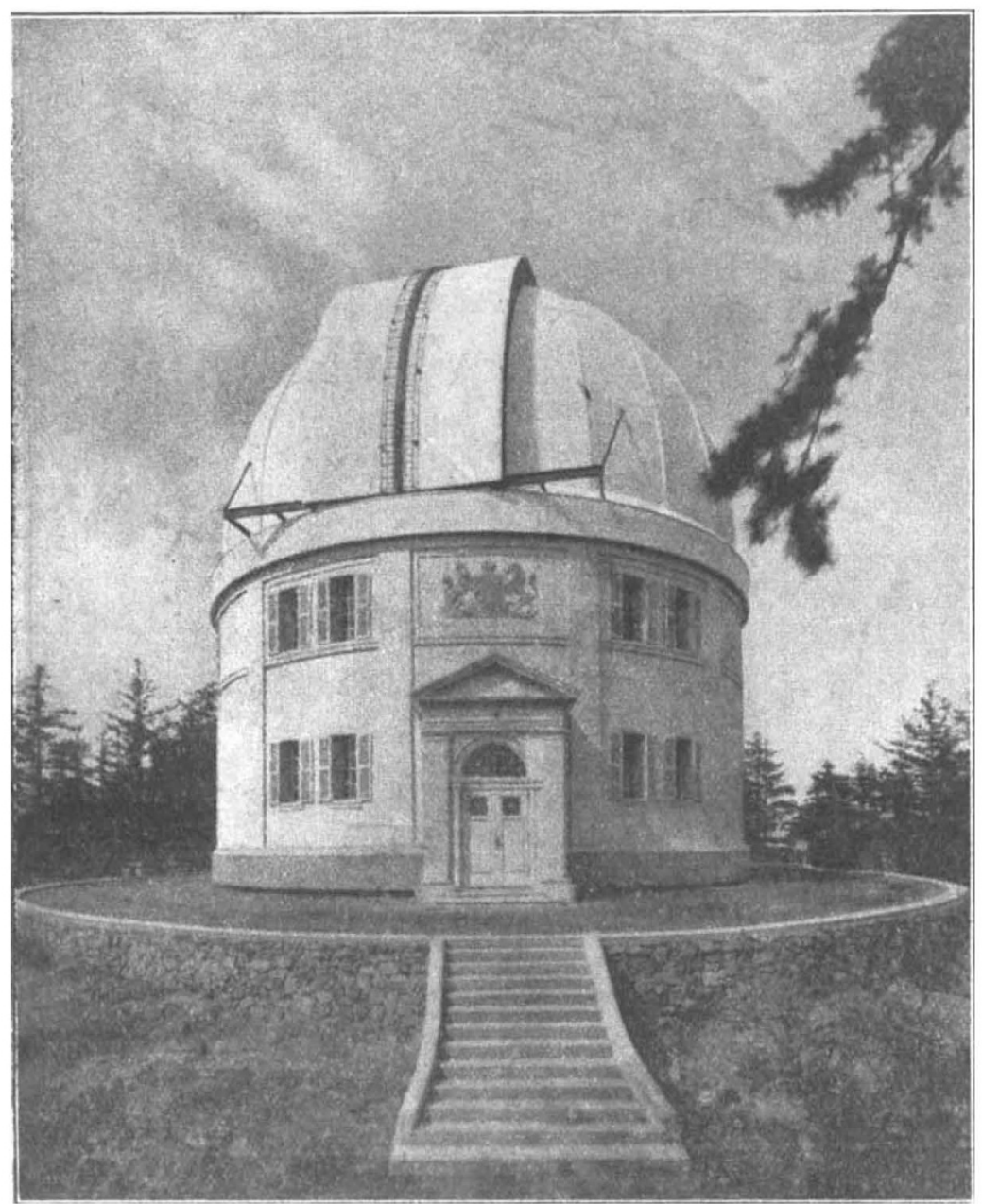

FIG. 1.-The observatory building from the south.

which gives every promise, so far as quality and efficiency of the equipment are concerned, of being a very large factor in astronomical research.

A preliminary description of the mounting of this telescope was given in NATURE of February $1_{5}$, I9I7, but its final completion last May, and its continuous use since then in regular observational work, merit a short statement of the quality of the optical parts and of the work being done and proposed to be done with this splendid instrument.

NO. 2580 , VOL. IO3]
The mounting was completely erected in its dome and building on Observatory Hill (Fig. I), about eight miles north of the city of Victoria, in October, 19r6, but the principal mirror and other optical parts of the telescope were not finished until April, rgr8. The delay was due partly to the impossibility of obtaining a large disc of glass for an auxiliary flat to be used in testing the figure of the paraboloid, and partly to the increased difficulty in figuring caused by the presence of the central hole in the main mirror. However, the figuring was finally completed early in April, I9I8, and on testing the mirror at the centre of curvature by visual measurements of the radius of curvature of several zones of the surface, and also by means of the Hartmann method of extra-focal photographic exposures, the whole surface was found to be remarkably close to the required theoretical form. The deviations of any part nowhere correspond with a greater longitudinal aberration at the principal focus than $0.25 \mathrm{~mm}$. (o.or in.), and this for a median zone. This is equivalent to a lateral aberration of less than one-tenth of this amount, or to a circle of confusion less than onethousandth of an inch in diameter, which, bearing in mind the size of the mirror, is a remarkable perfection of figure.

The mirror with other optical parts, which arrived in Victoria on April 29, was installed and collimated and the first star spectrum obtained on May 6. Considering the size and hitherto untried features of the telescope, this speaks well for the care used in the design and construction of both optical parts and mounting. The instrument has been used continuously since, mostly in obtaining stellar spectra, and has given the utmost satisfaction.

The tests of the figure of the mirror were obtained in the optical shop under constant temperature conditions, and it was of interest to determine its behaviour under average observing conditions in its dome. Although one of the reasons for the choice of Victoria as a site for the telescope was the low diurnal range of temperature, the total range in twenty-four hours rarely exceeding $5^{\circ} \mathrm{C}$., yet it was soon seen that even a smaller change than this introduced considerable aberration in the figure of the mirror. Hartmann tests made after a daytime rise of about $5^{\circ} \mathrm{C}$. showed a longitudinal aberration, under correction, of nearly $3 \mathrm{~mm}$., as compared with $0^{\circ} 25 \mathrm{~mm}$. 
under constant temperature. A similar test after a daytime rise of about $I^{\circ} 5^{\circ} \mathrm{C}$. showed longitudinal aberration of only about $0^{\circ} 5 \mathrm{~mm}$. This corresponds with a very good figure, and it was evident, if the best results were to be obtained, that some means should be adopted for reducing the change of temperature around the mirror. This was effected by permanently covering the closed section of the tube, consisting of two steel castings weighing more than ro tons, with felted cotton about 2 in. thick. The space between the back and edges of the-mirror and the bottom and sides of the cell was also packed with this felt; and a removable pad placed on thin boards laid across the top of the closed section, when the mirror is not open to the sky, completes the enclosure of the mirror.

During the daytime rise of temperature in the dome the 2 tons of glass in the mirror and the ro tons of steel in the centre section and cell of the tube are protected by this heat-insulating material, with the result that the change of temperature around the mirror is very slow. This change amounts to only about one-third of that in the dome, and does not often exceed $\mathrm{I}^{\circ} \mathrm{C}$., with the result that the aberration is always so small as to be negligible in increasing the size of the star image in comparison with the enlargement caused by atmospheric disturbances. The quality of the optical parts and their performance since the insulating cover was applied leave nothing to be desired, and although only a few direct photographs at the principal focus have yet been made, the definition is superb, the smallest images being but slightly more than a second of arc in diameter. For use with the spectrograph a Cassegrain combination is employed: the principal mirror of $7^{2}$-in. aperture and $30-\mathrm{ft}$. focus, and the convex secondary of 2o-in. aperture placed about $7 \mathrm{ft}$. within the principal focus. equivalent focal length is ro 8 ft, and it is sufficient evidence of both the optical quality and the seeing conditions to say that frequently the greater part of the star image appears to be lost in the spectrograph slit, which is $0^{\circ} 3 \mathrm{~mm}$. wide, and that a spectrum, of linear dispersion $35 \AA$. to the $\mathrm{mm}$. at $\mathrm{H} \gamma$, of a star of $7^{\circ} \mathrm{O}$ magnitude can be obtained in 20 to 25 minutes under average seeing conditions.

However good the optical parts, effective work could not be done unless the mechanical parts NO. 2580 , VOL. IO3] were so designed and constructed as rigidly and yet flexibly to carry the optical parts in their correct relative positions, and the mechanism so arranged as to enable the telescope to be pointed quickly and accurately to the desired position, and then to follow accurately the apparent motion of the star. This has been effected in the telescope in a remarkably efficient manner, and I have no hesitation in saying that this mounting sets a new standard for convenience and accuracy in operation. The telescope is set and guided by electric power having three speeds in each co-ordinate:

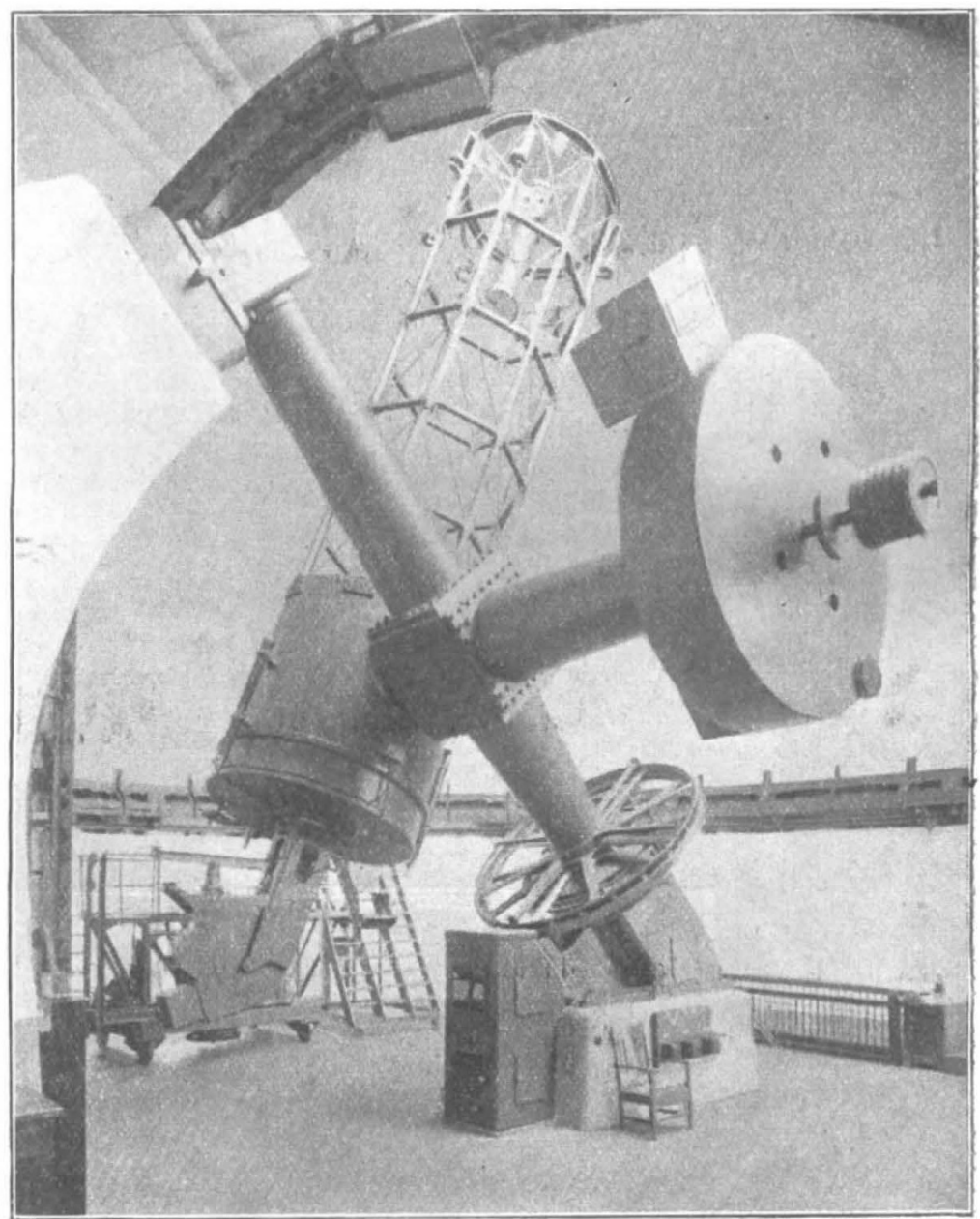

FiG. 2.-The telescope from the north-west.

a quick motion of $45^{\circ}$ per minute, a fine setting motion of $\mathrm{ro}^{\prime}$ per minute, and a guiding speed of $0^{\prime} 5^{\prime}$ per minute, one revolution in 8 minutes, 36 hours, and 30 days respectively. The quick motion and clamps are operated from duplicate switchboards on each side of the south pier (one of these can be seen in Figs. 2 and 3), while the fine setting and guiding is done from a small, portable board carried by the observer. No fine circles are provided, but the coarse circles are graduated to minutes of time in R.A., and to $5^{\prime}$ in declination. In consequence, the telescope can be set easily and 
quickly to within less than $2^{\prime}$ of the catalogue position, and identification is much simplified and charting becomes unnecessary generally for any stars brighter than, say, $7 * 5$ magnitude. The following given by the clock is remarkably smooth and accurate, without a trace of any periodic or other drift in the image, even with the great focal length of ro8 ft.; the guiding for the spectrograph is hence very easy. The slit of the spectrograph subtends angular dimensions $3^{\prime \prime}$ by $\mathrm{O}^{\prime} 3^{\prime \prime}$, and so accurate is the driving, and so small and sharp the image in good average seeing con-

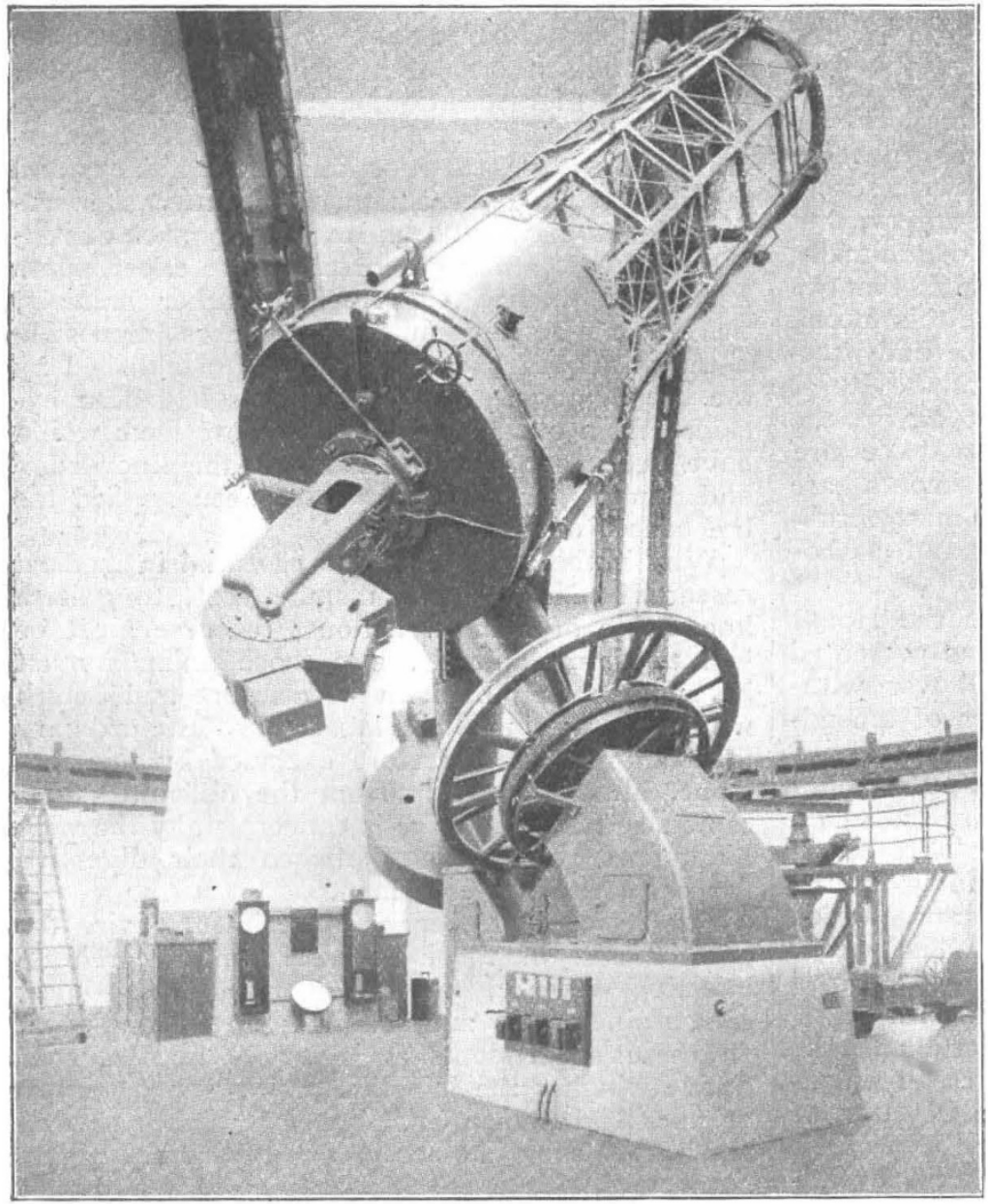

Fig. 3.-The telescope from the south-west.

ditions, that, unless the clock is set to drive slightly fast or slow, so that the image drifts slowly from one end to the other of the slit, the star spectrum would be too narrow or too unevenly exposed to be measurable.

Although the telescope can be easily operated by one person, ordinarily the observer is assisted by the night engineer, and it is a sufficient commentary on the perfection of the design and construction, and on the smoothness, ease, and accuracy of operation, to state that the average time required to change from star to star in No. 2580 , VOL. 103$]$ making spectra, the time from the end of one exposure to the beginning of the next, is less than three minutes, and if the stars are not far separated in the sky, frequently only two minutes. When a single person is operating, these times are increased about 50 per cent., and $I$ do not believe, notwithstanding the 45 tons weight of moving parts of this telescope, that one of onefifth the aperture is generally handled so expeditiously.

I should not be doing what is right and just if I failed to express my appreciation of the successful efforts of the builders of this telescope to make an instrument unequalled in quality, accuracy, and convenience. The John A. Brashear Co. for the optical parts, and the Warner and Swasey Co. for the mounting, have undoubtedly added materially to their already high reputation by their marked success in this great instrument, and my gratitude and that of all interested in the progress of science is due to them for the spirit in which they attacked the problems that confronted them, and by their refusal to be satisfied, no matter what the cost, by anything but the best possible.

As previously intimated, the greater part of the observing time of the telescope since completion has been occupied in making star spectra, I I 86 spectra of stars, on the average fainter than the 6th magnitude, having been obtained by December $3 \mathrm{r}$, I9I8. As a by-product in the measurement of some of these spectra, thirty spectroscopic binaries have been discovered. The present spectroscopic observing programme, arranged in cooperation with Mt. Wilson, consists of about 800 stars from Boss's "Preliminary General Catalogue," the purpose being to determine the radial velocity of all the stars in the catalogue not previously observed and within reach at the observatory and at Mt. Wilson in the shortest possible time. In addition, considerable time has been spent on a piece of work for the late Prof. Pickering, of Harvard, obtaining direct photographs of the Harvard regions with and without a parallel wire grating for the purpose of extending the magnitude scale in these regions to the faintest possible stars. Other work will, of course, develop as time goes on, but in the meantime, and considering the small staff--only the director and Dr. Young being at present avail- 
able-it was felt that the time of the telescope would be better devoted to these two pieces of direct, useful, and much-needed work than if it were, used in miscellaneous researches which, though possibly more interesting, would certainly not be so generally useful in the advancement of the science.

J. S. Plaskett.

\section{THE USE OF ANIMALS IN MEDICAL RESEARCH.}

$\mathrm{W}^{\mathrm{H}}$ EN a Bill to prohibit experiments on dogs was before the House of Commons in I9I4, a memorial signed by more than three hundred eminent physicians, surgeons, and other representatives of medical science, protesting against the measure, was addressed to the Home Secretary. The strong conviction was then expressed that the Bill would inflict very severe injury, not only on medicine and surgery, but also on the study of the diseases of animals; and the memorialists added: "We think that we have some right to ask you to oppose this attack on the advancement of medical science and practice, especially as the Final Report of the Royal Commission on Vivisection does not advise the prohibition of experiments on dogs. We are absolutely certain that such experiments are necessary for the complete study of many problems of physiology, pharmacology, and patho'ogy."

The second reading was carried in the House of Commons before this memorial was presented to the Home Secretary, but the Bill was withdrawn in June, I9I4, after a number of amendments to the principal clause had been carried in the Standing Committee appointed to consider it. The subject has, however, been raised again by the introduction of another "Dogs' Protection Bill," which received its second reading in the House of Commons on March 2I, and passed through the Grand Committee stage last week. Sir Edward Sharpey Schafer, Dr. T. Lewis, Prof. E. H. Starling, and Prof. Leonard Hill have stated the case against the Bill in letters to the Times, and we may be permitted to recall a convincing article by the first-named in NATURE of May 7, I9I4, where it is shown that the prohibition of the employment of dogs for certain investigations would put a complete stop to the progress of physiology in Great Britain.

The position now is much the same as in I9r4, and Sir Edward Sharpey Schafer's forcible statement in our columns of the case against the Bill is as applicable to the new measure as it was to the old. After the brilliant successes achieved during the war by physiological and scientific medicine in the preservation of life and the prevention of suffering in our armies, it might have been thought that the agitation against medical experiments on animals would have received its death-blow. But there are some people who are incapable of learning, and the passage of the NiO. 2580 , VOL. IO3]
Dogs' Protection Bill through the Grand Committee stage suggests that many of them are congregated in our legislature.

Do the supporters of the Bill really imagine that, since it has been proved possible to slaughter millions of human lives and to subject men and women to slow death by starvation, brutality, and disease, the value of human life has really become lower than that of a dog? For it must be remembered that the prevention and cure of disease are possible only by means of an accurate knowledge of the functions of the body, and that, with regard to these functions, there is scarcely any fundamental truth which has not been established by experiments on dogs. The action of the heart and its nerves, the circulation of the blood, the nature of respiration, the processes of digestion, the chemical changes which the food undergoes in the body, the functions of the kidneys and of the liver, and the action of the internal secretory glands, have all been revealed by such experiments. And, although corroborative experiments. have been carried out since on other animals, these would have been in many cases impossible if the principles had not first been established by the use of dogs. If these animals had been excluded from experiment, few of these facts would have been found out, nor would the knowledge and power gained thereby have been applied for the benefit of man.

Why is the use of dogs so essential in medical research? No one will dispute that, to gain a knowledge of living functions, recourse must be had to living animals, and those animals must be such as can be kept in comfort and health within the precincts of a laboratory. The ordinary farm animals are therefore excluded by this fact alone, altogether apart from the difficulties presented, so far as medicine is concerned, by the wide differences, which exist between their digestive processes and those of man.

For a vast number of experiments, viz. the greater part of those neressary in research on infective disease, the smaller animals-mice, rats, guinea-pigs, and rabbits-can be employed. In these experiments it is chiefly necessary to decide whether the injection of a given organism or microbial poison is followed by death or survival. As soon, however, as it becomes necessary to analyse the processes occurring in separate organs, e.g. the heart, the kidney, etc., it is essential to make use of larger animals, and the limitation mentioned above confines these to dogs and cats. Cats are used wherever possible. But the delicacy of their tissues, the small size of their organs, and the marked differences which exist between their food habits and those of man render it necessary to employ dogs for many important lines of research. Thus it comes about that the greater part of our knowledge of the heart's action, of the production of lymph and the causation of dropsy, of the nature of diabetes, and of the fate of different kinds of food in the body, is owing to experiments on dogs, and would 